\title{
Adolescência em contextos de (des)amparo: vivências e discussões relacionadas à droga
}

Adolescence in contexts of helplessness: experiences and discussions related to drugs

Edna Linhares Garcia, ${ }^{1}$ Mauriceia Eloisa Moraes, ${ }^{1}$ Julia Souza Moraes, ${ }^{1}$ Vitoria Merten Fernandes ${ }^{1}$ 'Universidade de Santa Cruz do Sul (Unisc), Santa Cruz do Sul, RS, Brasil.

Recebido em: 10/07/2017 / Aceito em: 19/09/2017 / Publicado em: 01/10/2017

edna@unisc.br

\section{RESUMO}

Este estudo propõe uma reflexão acerca da adolescência subjetivada em meio a um contexto permeado pelas vivências e pelos discursos relacionados à droga. Objetivo: evidenciar fatores que devem ser considerados na elaboração de estratégias de prevenção ao uso de drogas e a promoção de saúde, nesta dimensão da vida. Método: estudo qualitativo; trata-se de um recorte da pesquisa "Análise das Narrativas de adolescentes sobre drogas", desenvolvida desde 2015, cujos dados foram produzidos por meio da realização de grupos focais e analisados a partir da proposta teórico-metodológica de Spink. Propõem-se uma discussão sobre os referencias identificatórios e o contexto de vida dos adolescentes, tendo como base os referenciais da teoria psicanalítica. Resultados e considerações finais: constatamos a ausência de referenciais identificatórios que sustentem os processos de subjetivação e produzam efeitos no sentimento de reconhecimento de si; identificamos a presença constante da droga e da violência e a ausência de alusão aos serviços substitutivos em suas ofertas de Atenção e cuidados a esta população. Concluímos da necessidade de produzir um enlace entre a política de saúde mental e o contexto da adolescência por meio dos "CAPS ad" e "CAPS ia", fortalecendo estratégias intersetoriais e promovendo parcerias com os próprios adolescentes.

Palavras-chave: Adolescência; Drogas; Desamparo; Família; Território.

\begin{abstract}
This study proposes a reflection about the adolescence in the context permeated by the experiences and discourses related to the drug. Objective: to highlight factors that should be considered in the elaboration of strategies to prevent drug use and promote health in this dimension of life. Method: qualitative study; this is a clipping of the research "Analysis of the adolescents narratives about drugs", developed since 2015 whose data were produced through the formation of focus groups and analyzed from the theoretical-methodological proposal of Spink. It is proposed a discussion about the identification references and the life context of the adolescents, based on the references of psychoanalytic theory. Results and closing remarks: we verified the absence of identifying references that support the processes of subjectivities and produce effects in the sense of self-recognition; we identified the constant presence of drugs and violence and the lack of allusion to substitutive services in their care and attention offerings to this population. We conclude from the need to create a link between mental health policy and the context of adolescence through psychological services, strengthening strategies and promoting partnerships with adolescents themselves.
\end{abstract}

Keywords: Adolescence; Drugs; Helplessness; Family; Territory. 


\section{INTRODUÇÃO}

O título do presente artigo tem por finalidade convidar o leitor a uma reflexão acerca da profunda ambivalência afetiva que tem enlaçado os adolescentes em suas relações de vida, seja na escola, na comunidade, na família ou com qualquer de seus pares. Amparo e desamparo, neste sentido, são categorias dinâmicas, o que condiz com amparo em determinado momento da vida, em outro pode se configurar como desamparo. É sobre este dinamismo intenso de afetividades, de incertezas e de desencontros, tão presentes na adolescência contemporânea, que propomos a presente discussão.

O uso abusivo de drogas na adolescência e os fatores associados à prevenção nesta etapa da vida tem sido foco de reflexão em diversos lugares do mundo. ${ }^{1,2}$ Nosso objetivo, ao direcionar uma investigação cientifica sobre esta temática no âmbito da adolescência, não se dissocia da ideia de fomentar e sustentar práticas de promoção de saúde e prevenção de uso de drogas, amplamente discutida no campo social, político, educacional e acadêmico. Contudo, ao tomarmos como prerrogativa investigativa, a escuta direcionada aos jovens, buscamos fortalecer a construção de projetos preventivos sustentados nos discursos trazidos diretamente por eles.

A adolescência tem como característica principal as transformações biopsicossociais que se intensificam nesta etapa da vida, bem como, das adaptações ao meio e dos processos de construção da autonomia. ${ }^{3}$ No entanto, deve-se ressaltar que os aspectos culturais estão associados ao reconhecimento de padrões relacionados ao comportamento desses sujeitos num determinado contexto histórico. ${ }^{4}$ Considerar este fator é indispensável para a proposta reflexiva a que se atém o presente texto, uma vez que partimos do entendimento de uma adolescência dissociada do conceito negativo e restritivo, por vezes atribuído a este momento de vida.

O uso de drogas na adolescência tem constituído um importante foco de discussão para a saúde pública, o que está associado, em certa medida, ao reconhecimento de índices estatísticos que apontam o início do uso predominantemente nesta faixa etária e os aspectos de risco associados a esta precocidade. ${ }^{5,6}$

No Brasil, o uso de drogas licitas e ilícitas tem direcionado políticas públicas e programas preventivos. No ano de 2002 instaurou-se a Política do Ministério da Saúde para a Atenção Integral a Usuários de Álcool e Outras Drogas, ${ }^{7}$ seguido de programas de prevenção e cuidado voltados a comunidades que apresentem relação de dependência ou uso extremado de substancias.

A investigação que realizamos, da qual o presente artigo constitui um recorte, objetivou proporcionar encontros com adolescentes, a partir dos quais pudemos identificar, por meio de suas narrativas, como a temática das drogas perpassa os processos de subjetividade e as diversas relações que se estabelecem nesta dimensão da vida.

Subsidiados pela teoria psicanalítica, refletimos acerca do desamparo que atravessa o contexto relacional dos adolescentes, evidenciado ao longo do processo de produção de dados da pesquisa acima mencionada, bem como, acerca das prováveis implicações relacionadas ao lugar que a droga ocupa na organização psíquica dos adolescentes.

\section{MÉTODO}

A metodologia utilizada no desenvolvimento desta pesquisa teve cunho qualitativo, descritivo e exploratório de produção e análise de dados. A instrumentalização se deu a partir dos pressupostos investigativos dos grupos focais ${ }^{8}$ e a leitura dos dados sustentou-se na perspectiva da análise dos sentidos produzidos no cotidiano, propostos pela autora Mary Jane Spink. ${ }^{9}$ A produção da pesquisa foi autorizada pelo Comitê de Ética em Pesquisa sob parecer 907.289.

Participaram do processo de produção de dados, adolescentes escolares do município de Santa Cruz do Sul, considerando a faixa etária dos 12 aos 18 anos, conforme o Estatuto da Criança e do Adolescente (ECA), Lei 8.069. ${ }^{10}$ A participação se deu de forma aleatória, a partir da manifestação do desejo de participar da pesquisa, vinda dos próprios adolescentes; não se justificou desta forma critérios de inclusão e exclusão.

A produção de dados se deu na prática de grupos focais, realizados dentro do contexto escolar. Cada escola teve a formação de um grupo com até 10 estudantes adolescentes. Com este mesmo grupo foram então realizados 3 encontros com duração de até 60 minutos, considerando que os grupos sempre tiveram intervalos de uma semana até o encontro seguinte.

Entendeu-se nesta perspectiva a importância da metodologia de produção de dados, consolidada na pratica dos grupos focais, visto a possibilidade de escuta e a livre circulação da palavra entre os adolescentes, que desta forma, puderam dar voz a sentimentos e sentidos que são produzidos em suas relações de vida.

No contexto dos encontros realizados com os adolescentes, a problemática em torno do uso de drogas não foi mencionada por parte dos pesquisadores, dando espaço para um dialogo livre entre os pares e desta forma, analisando o mais neutramente possível, qualquer alusão à droga que pudesse se manifestar neste meio. Nesta perspectiva, os mediadores (pesquisadores) se fizeram presentes para as constatações da escuta e da interação entre os participantes, intervindo apenas quando necessário para realizar considerações ou propor o início de um diálogo.

A análise dos dados, ora produzidos no contexto dos grupos focais, foi realizada com base na teoria metodológica proposta por Mary Jane Spink, ${ }^{9}$ baseada na análise dos sentidos produzidos no cotidiano dos participantes da pesquisa. Após uma primeira escuta de todos os áudios gravados, foram então realizadas as transcrições e com isso, a continuação da análise dos dados.

Foram destacados elementos fundamentais e condizentes com a proposta da pesquisa nos discursos dos adolescentes, os quais, de maneira eficaz, puderam responder a proposta investigativa da pesquisa e dar conotação perspicaz aos objetivos ora mencionados.

\section{RESULTADOS E DISCUSSÕES}

\section{O lugar dos referenciais identificatórios na constituição psíquica do sujeito}

A adolescência é um período do desenvolvimento humano tida como marco fundamental na passagem da infância para a idade adulta, marcada categoricamente 
em nossa cultura como um espaço de ambivalência e transformação, seja no âmbito físico, social ou psicológico. ${ }^{11}$ É assinalada como principal estágio de busca pela identidade própria, desvinculada daquela que até então se construiu basicamente no âmbito familiar, tido como o único referencial identificatório que o sujeito tem até o período da adolescência.

É principalmente neste espaço de vida que o sujeito busca o pertencimento e a aceitação frente a determinados grupos, objetivando uma afirmação de si em contextos e relações específicas. É o tempo em que "vivencia a reconstituição de suas referências identitárias, que são localizadas entre a infância e o mundo adulto"(p. 825)..$^{12}$

Os referenciais identificatórios caracterizam, desde muito cedo, um marco fundamental na vida do sujeito. São constituídos pelas ofertas advindas daquelas pessoas que investem na criança desde a sua tenra infância, mas cujo processo de identificação com outros referenciais se estende ao longo da vida, ou seja, a identificação é um processo que, uma vez iniciado, somente cessa com o fim da vida. ${ }^{13}$ Os seus efeitos mais fortes, no entanto, se registram em momentos nos quais os conflitos de identificação estão mais proeminentes, como é o caso da adolescência, que na nossa cultura, impõe uma série de injunções e indefinições, tal como descreve Calligaris (2009, p.18): ${ }^{14}$

Em nossa cultura, a passagem para a vida adulta é um verdadeiro enigma. A adolescência não é só uma moratória mal justificada, contradizendo valores cruciais como o de autonomia. Para o adolescente, ela não é só uma sofrida privação de reconhecimento e independência, misteriosamente idealizada pelos adultos. É também um tempo de transição, cuja duração é misteriosa.

Ao longo da adolescência muitos referenciais são ofertados; no entanto, eles não provêm apenas do ambiente psíquico familiar, mas de outras relações e contextos sociais que portam o mesmo grau de importância para a constituição do sujeito. Assim, para além do âmbito familiar, a comunidade oferece suas referências e seus emblemas identificatórios, expressando o seu investimento no sujeito e, mostrando a ele, o quanto é desejado e como este desejo se manifesta, garantindo-Ihe um lugar de reconhecimento, desde que, em contrapartida, preste respeito aos valores desta comunidade.

Aulagnier ${ }^{13}$ denomina esta relação de Contrato Narcisista, que no inicio da vida tem os pais ou responsáveis como signatários, para em seguida ser assumido ou respondido pelo próprio sujeito envolvido: "O contrato narcisista se estabelece graças ao pré-investimento do infans pelo meio, como voz futura que ocupará o lugar que lhe será designado, dotando-o antecipadamente e por projeção do papel de sujeito do grupo" (p.150).

No entanto, para que o sujeito possa investir em emblemas identificatórios do meio social e não mais de um único outro ou de um único ambiente psíquico-familiar, é necessário que a oferta advinda deste contrato ofereça uma segurança recompensadora, ou seja, um prazer futuro e um futuro prazeroso. O discurso da comunidade e da sociedade deve, de maneira clara, oferecer ao sujeito a esperança de que ele se tornará valorizado pelo seu subgrupo, pela comunidade, pela sociedade e por si mesmo.

Mantidas e respeitadas as condições contratuais por ambas as partes, o desenvolvimento psíquico, possivelmente, se dará livre de fatores que implicam em defesas primitivas frente às exigências da sociedade, tal como podemos identificar nos casos do uso extremado de drogas, por exemplo.

Com efeito, considerando os adolescentes entrevistados, constatamos que tal contrato se encontra desrespeitado desde cedo, dadas as condições de vida a que são submetidos. Assim, torna-se difícil dimensionar os prejuízos para esses sujeitos que relatam a necessidade de abrir mão do convívio com suas origens, com seus pares sociais para poder garantir a vida. Os adolescentes participantes de nossa pesquisa trazem, em suas narrativas, conflitos referentes a isso, pois vivem em um contexto de violência, do qual desejam ir embora, e ao mesmo tempo, não se identificam e/ou não se reconhecem fora dessa realidade.

Pra mim, tipo assim, eu quero terminar meus estudos, depois eu quero ir embora aqui desta vila, quero ir embora. (14 anos)

Se eu puder falar de um sonho, meu sonho e poder me formar e poder tirar a minha família daqui (12anos)

Eu tenho um sonho de terminar os estudos e depois eu quero continuar aqui, eu nasci aqui, é aqui (13 anos)

“Eu vou começar de trabalhar e daí a metade do dinheiro eu vou guardar e daí eu vou pegar o meu irmão, ainda tenho um irmão e vou embora daqui, da vila, longe de tudo isso, dessa violência"(13 anos)

Os sentidos produzidos nos discursos dos adolescentes participantes da pesquisa, de modo geral, se assemelham às frases citadas acima. Observamos o desamparo frente à violência que os jovens vivenciam, retratado nas falas sobre seu cotidiano, medos e vivências relacionais. O meio nesse caso ajuda a legitimar o sentimento de desamparo e favorece experiências frágeis de investimento por parte do território ao adolescente.

A droga neste contexto surge como mecanismo de amparo ao sujeito, seja frente ao desolo dos investimentos não a eles direcionado, seja na própria ambientação e sustentação da vida em comunidade. Santos e Pratta ${ }^{15}$ apontam que "o ser humano, ao longo de sua existência, procura, de um lado, encontrar situações que lhe propiciem prazer e, de outro, que irão diminuir ou até mesmo eliminar certas condições que possam causar dor ou sofrimento" (p.174).

A comunidade não assegura a identificação de um investimento legitimo, ou seja, se torna improvável reconhecer-se investido, desejado ou querido em um território que oferece risco e iminente ameaça de morte. Com isso, pode-se refletir que a gênese da construção de uma representação de desamparo leva os adolescentes a construírem um discurso unívoco sobre a necessidade de partir para outro território que os possa receber com maior e melhor investimento.

\section{A presença de uma realidade que não neutraliza o ser rejeitado e os "ruídos" na constituição do sujeito}

Os sentidos que se produziram nas falas dos adolescentes participantes da pesquisa, de modo geral, apresentaram um cenário tensional, quando do encontro com o meio externo ao ambiente familiar do qual até então faziam parte. Este cenário é descrito enquanto 
espaço de hostilidade, agressão e decepção. No entanto, a realidade que se apresenta a eles neste contexto externo social já é histórica. Desde a tenra infância, estes adolescentes encontram comportamentos do meio, em exigir e oferecer, que os leva a reconhecer os signos de um "não desejo" e de um conflito constante. A ausência daquilo que lhes é de direito e de uma necessidade, passa a não garantir a relativização das fantasias do mundo da infância, que se apresentam em pares de opostos ao longo do processo de identificação, tal como exemplifica Aulagnier, ${ }^{13}$ quando se remete ao encontro materno:

[...] a significação e a manifestação do agir materno vão confirmar a legenda de uma fantasia que, de qualquer modo, seria produzida, mas ao lado de uma outra, de sentido contrário, na qual o desmame não equivaleria à mutilação de um prazer oral, limpeza não equivaleria à recusa de receber o dom excremental, ausência não equivaleria ao desejo de não ver o sujeito, de negar sua existência (p.279).

Os adolescentes entrevistados relatam o encontro com um mundo destituído de algo que possa desmentir as fantasias de rejeição, de abandono, de desamor. Procede refletir sobre a possibilidade de que a ressignificação das fantasias de rejeição não seja facilitada, ou, que tal ressignificação ocorra somente de modo rudimentar, tornando possível viver como traumáticas as mais diferentes experiências ao longo da vida e, especialmente, da adolescência. O contexto cotidiano favorece o sentimento de desamparo, “[...] as experiências comuns como o desmame, a aprendizagem do controle esfincteriano, a eventual doença ou o luto eventual, se transformarão em experiências traumáticas de uma história" (p. 279). ${ }^{13}$

Como pudemos constatar, nenhum dos sujeitos desse estudo esteve ao abrigo do encontro com um contrato narcisista viciado, rompido pela sociedade, desde a "pré-história" de seus pais, tios ou outros parentes, que se encontram em condições precárias de recursos para a necessidade de sobrevivência.

É verdade que não se pode mensurar o poder determinante de tal realidade para as desordens psíquicas, mas ao mesmo tempo, não é possível negar sua fundamental implicação nas perturbações que os sujeitos possam apresentar num futuro. Não há como desprezar a possibilidade de terem as injunções e exclusões sociais sido vividas como uma confirmação de suas fantasias de rejeição, de abandono e de desafeto, próprias do mundo adolescente. Constatamos que a realidade histórica que os sujeitos deste estudo trazem, é demasiadamente facilitadora para que os fantasmas pressuponham uma realidade. ${ }^{16}$

Reflexões sobre o alcance da Política Nacional de Promoção da Saúde, no âmbito da adolescência

A Política Nacional de Promoção da Saúde ${ }^{17}$ aborda a importância de um trabalho em rede para o exercício da cidadania e da qualidade de vida dos indivíduos (p.11). O trabalho em saúde, baseado nas prerrogativas desta política, se da na articulação e na participação responsável do Estado, dos trabalhadores, dos serviços, instituições sociais e do coletivo comunitário.

Entendemos a promoção de saúde, enquanto um compartilhamento de estratégias, de conhecimentos e de serviços para a estruturação da cidadania e do bem coletivo. Buchele, Coelho e Lindner ${ }^{18}$ descrevem que esta política "[...] é associada a um conjunto de valores, tais como vida, solidariedade, equidade, democracia, cidadania, desenvolvimento, participação, parceira, entre outros" (p.268).

$\mathrm{Na}$ presente pesquisa, os adolescentes desenharam um cenário bastante diferente daquele proposto pela política nacional de promoção da saúde. A leitura trazida por eles sobre o território micro e macro social que os envolve, de modo geral, apresenta uma realidade de distanciamento entre as partes que deveriam estar unidas na formulação e na conjuntura de estratégias de promoção de saúde.

Quando perguntados sobre as possibilidades ofertadas na comunidade para promoção de lazer, educação, saúde e qualidade de vida, os adolescentes trouxeram de forma perspícua, a questão da descontinuidade. Projetos sociais, redes de apoio a saúde e a educação foram citados como importantes elementos para a vida dos adolescentes, no entanto, os projetos levados para a comunidade não apresentam continuidade colaborativa e terminam antes mesmo da adequação de grande parte dos adolescentes ou de seus familiares.

“Nós sentimos falta de um espaço diferente da sala de aula, deveria ser todo dia alguma coisa" (12 anos)

"Em outro turno da escola não tem oportunidade, aqui é só estudar." (13 anos)

“Já teve judô, mas já não tem mais, até tem os tatamis ainda, mas acabou" (14 anos)

"Aqui deveria ter algo a mais do que só estudar" (14 anos)

Esta questão nos leva a refletir sobre a descontinuidade de investimentos que a própria comunidade destina aos jovens. Neste aspecto, não somente a comunidade de território do qual fazem parte, mas do âmbito social que deixa de investir logo que os projetos comecem a dar resultados. Esta falta no entanto, é percebida cotidianamente pelos adolescentes, nas suas relações de vida na comunidade.

A temática das drogas foi amplamente citada por parte dos adolescentes, principalmente nos discursos que trouxeram experiências de vida e sequencialidade de projetos de futuro dentro e fora do ambiente territorial do qual fazem parte. Os sentidos produzidos pelos adolescentes sobre a questão das drogas, mostram que as relações com as substâncias vão além do uso, ou seja, fazem parte das experiências de vida de cada um deles. Ressalta-se neste aspecto que os jovens assumem um posicionamento frete os diferentes aspectos e problemáticas que envolvem o cenário da drogadição, considerando desde o uso, até a produção e a comercialização das substâncias.

Observou-se, no entanto, que em nenhum momento os serviços substitutivos de atenção à saúde mental foram citados durante os grupos focais com os adolescentes. Esse fenômeno nos convida a pensar sobre o posicionamento e o investimento da saúde mental para com o jovem, que embora tenha citado complexidades voltadas à drogadição e à vida conturbada pela violência na comunidade, não menciona os serviços de saúde como referência de apoio.

Os serviços substitutivos para o cuidado em saúde mental, como os CAPS (Centro de Atenção Psicossocial) e os NAPS (Núcleo de Atenção Psicossocial) ${ }^{19}$ sur- 
gem no contexto da Luta Antimanicomial e da Reforma Psiquiátrica, a partir dos anos 80 . Em 2002, através da Portaria $n^{\circ} 336 / G M$, se regulamentaram esses serviços, estabelecendo o funcionamento nas modalidades de CAPS I, CAPS II e CAPS III, além do funcionamento dos CAPS i e CAPSad, sendo estes o CAPS para infância e adolescência e o CAPS para álcool e outras drogas.

\section{CONSIDERACQÕES FINAIS}

Sempre parece haver um impasse do significado e das condições que promulgam o significado de adolescência. Consideramos que esta etapa do ciclo vital tem um parâmetro cultural fundante, ou seja, para pensar a adolescência, há que se propor a reflexões acerca do espaço sociocultural, onde ela está inserida. A partir desta perspectiva, partimos da ideia de uma adolescência não negativada, ou seja, suposta de potencialidades e de constituições aprimoradas a seu cenário de vida.

É neste contexto que refletimos sobre a questão das drogas e da drogadição, considerando que o adolescente por vezes tem um referencial de vida absolutamente permeado pelas substâncias, seja no uso, na produção ou na comercialização. Este fator implica em um posicionamento que toma como principio um cenário de vida, onde a droga oferta empoderamento e na mesma proporção, risco à saúde e a vida dos indivíduos.

O fato de apontar o desamparo como fator imponente na qualidade de vida e na produção de subjetividade do adolescente caracteriza-se não apenas a um contexto de vida familiar, mas ao investimento social e comunitário para com o individuo que necessita deste para o aprimoramento psíquico e, por vezes, encontra na substância um amparo condicionante.

É fato que o investimento do outro é primordial na construção e no reconhecimento do ser investido, ou seja, o sujeito se reconhece também pelo olhar do outro e pelos recursos que o outro oferece a ele no dia a dia, seja como investimento micro ou macro social.

Amparo e desamparo são faces de um amplo cenário de investimentos que o sujeito tem, ou não, desde a tenra infância. A questão das drogas pode aparecer, neste sentido, como propulsora de preenchimento para um espaço de vazio não investido, familiar e socialmente. Os investimentos da sociedade e da comunidade, para com os jovens, necessitam de um aprimoramento constante, de uma sustentação que permita o reconhecimento do investimento do outro. A isso se aplicam os trabalhos multidisciplinares e intersetoriais, entre as dimensões da educação, saúde, lazer, cultura e cidadania, sempre em beneficio de uma melhor qualidade de vida.

\section{REFERÊNCIAS}

1. Bittencourt ALP, França LG, Goldim JR. Adolescência vulnerável: fatores biopsicossociais relacionados ao uso de drogas. Rev Bioét 2015;23(2):311-19. doi:10.1590/198380422015232070

2. Vinet EV, Faúndez $X$. Consumo de alcohol y drogas en adolescentes evaluado a través del MMPI-A. Salud Ment
(Mex) 2012;35(3):205-13.

3. Morgado AM, Dias MLV. Comportamento antissocial na adolescência: o papel de características individuais num fenómeno social. Psic Saúde \& Doenças 2016;17(1):15-22. doi: 10.15309/16psd170103

4. Macedo EOS, Conceição MIG. Significações sobre Adolescência e Saúde entre Participantes de um Grupo Educativo de Adolescentes. Psicologia: Ciência e Profissão 2015;35(4):1059-73. doi: 10.1590/1982-3703000552014

5. Garcia EL, Zacharias DG, Winter GF, Sontag J. (RE)conhecendo o perfil do usuário de crack de Santa Cruz do Sul. Barbarói 2012;36(ed. especial):83-95. doi:10.17058/barbaroi.v0i36.2922

6. Cerutti F, Ramos SP, Argimon. IIL. A implicação das atitudes parentais no uso de drogas na adolescência. Acta Colombiana de Psicología 2015;18(2):173-81. doi: 10.14718/ ACP.2015.18.2.15

7. Brazil. Ministério da saúde. A política do Ministério da Saúde para a atenção integral a usuários de álcool e outras drogas. Ministério da Saúde, 2004.

8. TradLeny A. Bomfim. Gruposfocais: conceitos, procedimentos e reflexões baseadas em experiências com o uso da técnica em pesquisas de saúde. Physis 2009;19(3):777-96. doi: 10.1590/S0103-73312009000300013

9. Spink MJ. Linguagem e produção de sentidos no cotidiano. Rio de Janeiro: Centro Edelstein de Pesquisas Sociais, 2010.

10. Brasil. Estatuto da criança e do adolescente (1990). Estatuto da criança e do adolescente recurso eletrônico: Lei n. 8.069, de 13 de julho de 1990, e legislação correlata. - 13. ed. Brasília : Câmara dos Deputados, Edições Câmara, 2015.

11. Senna SRCM, Dessen MA. Reflexões sobre a saúde do adolescente brasileiro. Psic Saúde \& Doenças 2015; 16(2):217-29. doi: 10.15309/15psd160208

12. Bertol CE, Souza $M$ de. Transgressões e adolescência: individualismo, autonomia e representações identitárias. Psicologia: Ciência e Profissão 2010;30(4):824-39. doi: 10.1590/S1414-98932010000400012

13. Aulagniere P. Observações sobre a estrutura psicótica. In: Katz CS. (Org) et al. Psicose - Uma leitura psicanalítica. 2 ed. São Paulo: Escuta, 1991.

14. Calligaris C. A adolescência. Publifolha, 2009.

15. Santos MA, Pratta EMM. Adolescência e uso de drogas à luz da psicanálise: sofrimento e êxtase na passagem. Tempo psicanalítico 2012;44(1):167-82.

16. Violante Maria Lucia Vieira. A indissociabilidade entre as dimensões psíquica e social na constituição psíquica do sujeito. Psicologia Revista. Revista da Faculdade de Ciências Humanas e da Saúde 2010;19(1)59-77.

17. Brasil. Ministério da Saúde. Secretaria de Vigilância em Saúde. Secretaria de Atenção à Saúde. Política Nacional de Promoção da Saúde / Ministério da Saúde, Secretaria de Vigilância em Saúde, Secretaria de Atenção à Saúde. - 3. ed. - Brasília: Ministério da Saúde, 2010.

18. Büchele F, Coelho EBS, Lindner SR. A promoção da saúde enquanto estratégia de prevenção ao uso das drogas. Ciênc Saúde Coletiva 2009;14(1):267-73. doi: 10.1590/S141381232009000100033

19. Brasil. Ministério da Saúde. Secretaria de Atenção à Saúde. DAPE. Coordenação Geral de Saúde Mental. Reforma psiquiátrica e política de saúde mental no Brasil. Documento apresentado à Conferência Regional de Reforma dos Serviços de Saúde Mental: 15 anos depois de Caracas. OPAS. Brasília, novembro de 2005. 